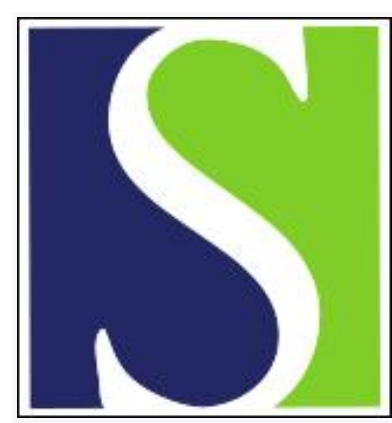

Scand J Work Environ Health 1994;20(5):345-348

https://doi.org/10.5271/sjweh.1387

Issue date: 01 Oct 1994

Gender ratio of offspring and exposure to shortwave radiation among female physiotherapists.

by Guberan E, Campana A, Faval P, Guberan M, Sweetnam PM, Tuyn JW, Usel M

Affiliation: Medical Branch of Labour Inspection, Geneva, Switzerland.

This article in PubMed: www.ncbi.nlm.nih.gov/pubmed/7863298

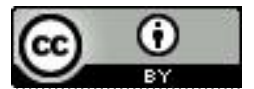




\title{
Gender ratio of offspring and exposure to shortwave radiation among female physiotherapists
}

\author{
by Etienne Gubéran, MD, ${ }^{1}$ Aldo Campana, MD, ${ }^{2}$ Pierre Faval, ${ }^{3}$ Martine Gubéran, ${ }^{4}$ \\ Peter M Sweetnam, MSc, ${ }^{5}$ Jan WN Tuyn, MSc, ${ }^{6}$ Massimo Usel, MSc ${ }^{1}$
}

\begin{abstract}
GUBÉRAN E, CAMPANA A, FAVAL P, GUBÉRAN M, SWEETNAM PM, TUYN JWN, USEL M. Gender ratio of offspring and exposure to shortwave radiation among female physiotherapists. Scand $J$ Work Environ Health 1994;20:345-8.
\end{abstract}

\begin{abstract}
OвJECTives - The goal of this study was to investigate whether the deficit of male births found among the offspring of Danish physiotherapists exposed to shortwave radiation during the first month of their pregnancy could be confirmed among the offspring of physiotherapists from Switzerland.

Methods - A self-administrated questionnaire was mailed (two mailings) to all of the 2846 female members of the Swiss Federation of Physiotherapists. It included questions on the gender and birthweight of all children of the physiotherapists, as well as on the use of shortwave or microwave equipment during the first month of each pregnancy. The response rate was $79.5 \%$, and the analysis was based on 1781 pregnancies.

REsults - The gender ratio (the number of males per number of females $\times 100$ ) was 107 with a $95 \%$ confidence interval $(95 \% \mathrm{Cl})$ of $89-127$ for the 508 pregnancies exposed to shortwave radiation and $101(95 \% \mathrm{CI} 90-113)$ for the 1273 unexposed pregnancies. There was no trend in the gender ratio with increasing intensity or duration of exposure. The prevalence of low birthweight $(\leq 2500$ g) was not related to exposure to shortwave radiation for either the boys or the girls.

Conclusions - No atypical gender ratio was found for the children of female physiotherapists from Switzerland who had been exposed to shortwave radiation at the beginning of pregnancy. The findings of the Danish study could not be confirmed.
\end{abstract}

KEY TERMS - birthweight, electromagnetic radiation, epidemiology, male embryo, microwave diathermy, pregnancy outcome, reproductive hazard.

In a case-referent study among the female members of the Union of Danish Physiotherapists, Larsen et al $(1,2)$ investigated the reproductive hazards of exposure to high-frequency electromagnetic radiation from shortwave diathermy. No significant association was found between various indices of exposure and congenital malformations, spontaneous abortion or stillbirth and death within one year. However, an association was found between exposure during the first month of pregnancy and a deficit of male births. The gender ratio (number of males per number of females $\times 100$ ) of offspring was 151 for the physiotherapists with no exposure, 48 for those with low exposure, and 31 for those with high exposure. The

1 Medical Branch of Labour Inspection, Geneva, Switzerland.

2 Clinic of Sterility and Gynecologic Endocrinology, University Hospital, Geneva, Switzerland.

3 School of Physiotherapy, Geneva, Switzerland.

4 Physiotherapist, Mézières, Switzerland.

5 MRC Epidemiology Unit, Penarth, South Wales, Great Britain.

6 European Organization for Nuclear Research CERN, Geneva, Switzerland.

Reprint requests to: Dr E. Gubéran, médecin inspecteur du travail, rue Ferdinand-Hodler 23, CH-1207 Geneva, Switzerland. trend was significant at the $0.1 \%$ level. In addition there was an association, although not significant, between exposure and low birthweight among the boys, while there was no such association among the girls. To explain the deficit of male births among the offspring of exposed physiotherapists, it was suggested that this type of electromagnetic radiation could induce very early abortion at a preclinical stage. This occurrence would mainly involve male embryos, which are considered to be more fragile than female ones.

The aim of the present study was to investigate whether the findings by Larsen et al could be confirmed among physiotherapists from Switzerland.

\section{Subjects and methods}

In Switzerland, about $95 \%$ of self-employed physiotherapists and about $60 \%$ of salaried physiotherapists are members of the Swiss Federation of Physiotherapists. A questionnaire was sent to all of the 2846 female members of that federation in November 1992 and a second time in the spring of 1993 to those who did not answer the first request. The physiotherapist was questioned on the gender and the birthweight of all her children, whether born alive or dead. Abortions were excluded because the gen- 
der of the fetus was unknown. The physiotherapist was also asked to report for each pregnancy whether she had been exposed to shortwaves during the first month and whether the equipment had been used by her or any colleague. Further questions asked for estimates of the duration of exposure per week at distances from the equipment of $1 \mathrm{~m}$ or less and of more than $1 \mathrm{~m}$. The different types of electrodes, as well as the relative percentages of them was also requested. The limit of $1 \mathrm{~m}$ was chosen because the electric field strength was shown to fall to $10 \%$ at $1.0 \mathrm{~m}$ and to $2 \%$ at $2.0 \mathrm{~m} \mathrm{(3).} \mathrm{An} \mathrm{additional} \mathrm{question} \mathrm{con-}$ cerned exposure to microwave radiation.

The questionnaire was returned by 2263 physiotherapists $(79.5 \%)$, of which 1187 responded by indicating that they had no children, 1030 had one child or more, and 46 either indicated unwillingness to participate or gave uninterpretable answers. The analysis was based on 1781 pregnancies, of which $54 \%$ had occurred during the last decade (1983-1992), $31 \%$ during the preceding decade (1973-1982), and $15 \%$ before 1973 .

Measurements in Denmark $(3,4)$ and Geneva (table 1) indicated that exposure to electromagnetic radiation is very low for the circuplode electrode. This is also the case for the other types of electrode at a distance of $1 \mathrm{~m}$ or more. The results were thus analyzed separately for the relatively highly exposed subgroup (ie, those exposed to monode, diplode or plate electrodes at a distance of $1 \mathrm{~m}$ or less).

For more than one century, the gender ratio of live births in Switzerland has been remarkably stable at around 105 . We have assumed that this figure is the "true" gender ratio of the offspring of unexposed physiotherapists. The $95 \%$ confidence interval $(95 \%$ CI) for the gender ratio among various subgroups of

Table 1. Power density values measured for different electrodes with a type Curaplus $\mathbf{4 1 9}$ diathermy unit.

\begin{tabular}{lcc}
\hline & $\begin{array}{c}\text { Equivalent plane wave } \\
\text { power density } \\
\text { Type of electrode }\end{array}$ & \multicolumn{2}{c}{$\left.\mathrm{mW}^{-2}\right)$} \\
\cline { 2 - 3 } & $30 \mathrm{~cm}^{\mathrm{a}}$ & $100 \mathrm{~cm}^{\mathrm{a}}$ \\
\hline Plate electrodes (Schliephake) & 200.0 & 2.0 \\
Diplode & 20.0 & 1.5 \\
Circuplode & 1.0 & $<0.1$ \\
\hline
\end{tabular}

a Distance from the electrode.

Table 2. Gender ratio a of the offspring of physiotherapists by occupational exposure to shortwaves during the first month of pregnancy. ( $95 \% \mathrm{Cl}=95 \%$ confidence interval)

\begin{tabular}{|c|c|c|c|c|}
\hline \multirow{2}{*}{ Group } & \multicolumn{2}{|c|}{ Number of births } & \multirow{2}{*}{$\begin{array}{c}\text { Gender } \\
\text { ratio }\end{array}$} & \multirow{2}{*}{$95 \% \mathrm{Cl}^{\mathrm{r}}$} \\
\hline & Males & Females & & \\
\hline $\begin{array}{l}\text { Unexposed } \\
\text { Exposed }\end{array}$ & $\begin{array}{l}641 \\
262\end{array}$ & $\begin{array}{l}632 \\
246\end{array}$ & $\begin{array}{l}101 \\
107\end{array}$ & $\begin{array}{l}90-113 \\
89-127\end{array}$ \\
\hline Total & 903 & 878 & 103 & $94-113$ \\
\hline
\end{tabular}

a The number of males per the number of females $\times 100$. physiotherapists has been calculated with the use of the exact binomial confidence limits from Geigy Scientific Tables (5).

From our knowledge, the type of equipment used for shortwave diathermy in Switzerland is similar to that used in Denmark. Larsen \& Skotte extensively studied the exposure of Danish physiotherapists giving diathermy $(3,4)$. By a limited series of measurements in Geneva, we were able to verify that the exposure of physiotherapists from Switzerland was likely to be of the same order of magnitude as that of their colleagues in Denmark.

Measurements were carried out in the vicinity of one of the diathermy installations of the School of Physiotherapy, Geneva, being of the type Curaplus 419 operating at $600 \mathrm{~W}$ peak power $(260 \mathrm{Weff})$ and a frequency of $27.12 \mathrm{MHz}$, to determine the potential radiofrequency exposure of therapists during treatment. These measurements were carried out with a Narda model 8608 broadband isotropic radiation monitoring system using a model $8662 \mathrm{~B}$ probe which measures the $\mathrm{E}$ field.

The measurements were made under normal operating conditions with the electrodes placed on the legs of a patient. Exposure was determined at distances of 30 and $100 \mathrm{~cm}$ from the electrode next to the patient. The results are given in table 1 . These values should be considered as upper limits of exposure since measurements of the $\mathrm{H}$ field showed considerably lower values at the same distances. It can be seen that exposure is a strong function of the type of electrode used, particularly at the shorter distance.

Moreover, it can be postulated that, due to the introduction of the circuplode electrode in the early 1970s, exposure of physiotherapists has been lower during the last two decades than beforehand.

\section{Results}

As shown in table 2, the gender ratio of offspring was 107 (95\% CI 89-127) for physiotherapists exposed to shortwaves at the beginning of pregnancy, whereas it was 101 (95\% Cl 90-113) for unexposed physiotherapists. The gender ratio was neither related to the type of electrode (on which the intensity of the electromagnetic field mainly depends) (table 3 ) nor to the duration of exposure (table 4$)$. The prevalence of low birthweight $(\leq 2500 \mathrm{~g})$ was not related to exposure among either the boys or the girls (table 5). Among all of the subgroups exposed to shortwaves, and among the physiotherapists exposed to microwaves (table 6 ), the $95 \%$ confidence interval of the gender ratio included the expected population value of 105 .

There was no significant difference between the exposed and unexposed physiotherapists (chi-square test) in the gender ratio of offspring (tables 2 and 6) or in the prevalence of low birthweights of offspring 
(table 5). Moreover the analysis by three periods of birth (1983-1992, 1973-1982, and before 1973) did not show a trend in the gender ratio of offspring among all of the physiotherapists and among the exposed or the unexposed groups.

\section{Discussion}

In the present study, there was no suggestion of a deficit of male births or of an increased prevalence of low birthweight of boys among the offspring of physiotherapists exposed to shortwave radiation in Switzerland at the beginning of pregnancy. This result is contrary to the finding of Larsen et al in Denmark. Among Danish physiotherapists the finding of a significant trend in the gender distribution of the offspring with increasing exposure to electromagnetic radiation was strongly influenced by the extraordinary gender ratio of 151 in the unexposed group (time-weighted exposure index $=0$ ). The $95 \%$ confidence interval for that ratio is 112 to 206 , whereas the gender ratio for all births in Denmark is 105.8 (1). Nevertheless, Larsen et al also found a large deficit of male births in their exposed group (timeweighted exposure index $=1$ and 2), for whom the gender ratio was only 42 . The current study was large enough to have a power in excess of $99 \%$ to detect, as significant at the $1 \%$ level, a decrease in the gender ratio to Larsen's value of 42 . However we found no suggestion of any deficit in male births.

Animal experiments with pregnant rats or mice exposed to shortwave or microwave radiation have shown increases in malformations and in embryo lethality, as well as reduction in fertility (1). It remains unclear, however, whether these adverse outcomes were only due to the well-known harmful effects of hyperthermia or whether they could be attributable to a possible nonthermal effect of electromagnetic radiation (1). The gender ratio of the offspring was not reported in these studies.

Two previous studies $(6,7)$ have addressed the possible reproductive hazard of various types of equipment used by female physiotherapists, but none has included an analysis of the gender ratio. In the first study, the frequency of use of shortwave equipment was significantly associated with congenital malformations in Finland, but only in the lower exposure group (6). In the second study, there was an association of borderline significance between frequent exposure to shortwaves and dead or malformed infants in Sweden, but there was little evidence that this association was causal (7). In neither of the studies, however, was the type of electrode taken into account to classify the exposure of physiotherapists, even though this is an extremely important variable.

In conclusion, the evidence from the available studies that occupational exposure of female physiotherapists to shortwave radiation may be harmful to their offspring is not conclusive.
Table 3. Gender ratio of the offspring of physiotherapists exposed to shortwaves, by type of electrode and by distance from the electrode. ( $95 \% \mathrm{Cl}=95 \%$ confidence interval)

\begin{tabular}{|c|c|c|c|c|}
\hline \multirow{2}{*}{ Type of electrode } & \multicolumn{2}{|c|}{ Number of births } & \multirow{2}{*}{$\begin{array}{l}\text { Gender } \\
\text { ratio }\end{array}$} & \multirow{2}{*}{$95 \% \mathrm{Cl}$} \\
\hline & Males & Females & & \\
\hline \multicolumn{5}{|l|}{ All distances } \\
\hline $\begin{array}{l}\text { Circuplode } \\
\text { Monode, diplode } \\
\text { Plate electrodes } \\
\text { Unspecified }\end{array}$ & $\begin{array}{l}16 \\
86 \\
85 \\
75\end{array}$ & $\begin{array}{l}16 \\
72 \\
73 \\
85\end{array}$ & $\begin{array}{r}100 \\
119 \\
116 \\
88\end{array}$ & $\begin{array}{l}47-214 \\
86-165 \\
84-161 \\
64-122\end{array}$ \\
\hline \multicolumn{5}{|l|}{ Distance $\leq 1 \mathrm{~m}$} \\
\hline $\begin{array}{l}\text { Circuplode } \\
\text { Monode, diplode } \\
\text { Plate electrodes }\end{array}$ & $\begin{array}{l}14 \\
69 \\
64\end{array}$ & $\begin{array}{l}15 \\
66 \\
61\end{array}$ & $\begin{array}{r}93 \\
105 \\
105\end{array}$ & $\begin{array}{l}42-207 \\
73-148 \\
73-151\end{array}$ \\
\hline
\end{tabular}

a With or without exposure to circuplode.

b With or without exposure to any other type of electrode.

Table 4. Gender ratio of the offspring of physiotherapists with relatively high exposure a to shortwaves, by duration and by type of exposure. ( $95 \% \mathrm{Cl}=95 \%$ confidence interval)

\begin{tabular}{|c|c|c|c|c|}
\hline & \multicolumn{2}{|c|}{ Number of births } & \multirow{2}{*}{$\begin{array}{l}\text { Gender } \\
\text { ratio }\end{array}$} & \multirow{2}{*}{$95 \% \mathrm{Cl}$} \\
\hline & Males & Females & & \\
\hline \multicolumn{5}{|l|}{ Duration } \\
\hline $\begin{array}{l}\leq 1 \mathrm{~h} \\
1-10 \mathrm{~h} \\
>10 \mathrm{~h}\end{array}$ & $\begin{array}{r}78 \\
48 \\
7\end{array}$ & $\begin{array}{r}82 \\
39 \\
6\end{array}$ & $\begin{array}{l}95 \\
123 \\
117^{b}\end{array}$ & $\begin{array}{c}69-131 \\
79-193 \\
\ldots\end{array}$ \\
\hline \multicolumn{5}{|l|}{ Type } \\
\hline $\begin{array}{l}\text { Only directc } \\
\text { Only indirect } \\
\text { Both }\end{array}$ & $\begin{array}{r}36 \\
3 \\
94\end{array}$ & $\begin{array}{r}34 \\
1 \\
92\end{array}$ & $\begin{array}{l}106 \\
300^{\circ} \\
102\end{array}$ & $\begin{array}{c}64-174 \\
\cdots \\
76-138\end{array}$ \\
\hline
\end{tabular}

a Subgroup exposed at $\leq 1 \mathrm{~m}$ from the monode, diplode, or plate elec trodes.

- Too few data to justify interval estimation.

c Shortwave equipment used by the subject only.

d Shortwave equipment used by colleague(s) only.

Table 5. Prevalence of low birthweight of $\leq 2500 \mathrm{~g}$ of the offspring ${ }^{\text {a }}$ of physiotherapists by exposure to shortwaves.

\begin{tabular}{lrrrrrr}
\hline \multirow{2}{*}{ Group } & \multicolumn{3}{c}{ Low birthweight } \\
\cline { 2 - 3 } \cline { 7 - 8 } & \multicolumn{2}{c}{ Males } & & \multicolumn{2}{c}{ Females } \\
\cline { 2 - 3 } \cline { 6 - 7 } & $\mathrm{N}$ & $\%$ & & $\mathrm{~N}$ & $\%$ \\
\hline Unexposed & 25 & 4.3 & & 36 & 6.1 \\
Exposed (all) & 11 & 4.4 & & 14 & 5.9 \\
Subgroup with high exposure & & 7 & 5.6 & & 7 & 5.7 \\
\hline
\end{tabular}

a Twins excluded.

- Exposed at $\leq 1 \mathrm{~m}$ from the monode, diplode, or plate electrodes.

Table 6. Gender ratio of the offspring of physiotherapists by exposure to microwave radiation. $(95 \% \mathrm{Cl}=95 \%$ confidence interval)

\begin{tabular}{lrccc}
\hline Group & \multicolumn{2}{c}{ Number of births } & Gender & $95 \% \mathrm{Cl}$ \\
\cline { 2 - 5 } & Males & Females & ratio & 96 \\
\hline Unexposed & 794 & 748 & 106 & $96-117$ \\
$\begin{array}{l}\text { Exposed } \\
\begin{array}{l}\text { Subgroup with high } \\
\text { exposure }\end{array}\end{array}$ & 67 & 79 & 85 & $61-118$ \\
\hline
\end{tabular}

a Doing $\geq 10$ treatments per week. 


\section{Acknowledgments}

We are grateful to the members of the Swiss Federation of Physiotherapists, particularly to the president $\mathrm{Mr} \mathrm{M}$ Borsotti, for their cooperation, to Professor MA Cooke (Birmingham) for his critical review of the manuscript, to Mr P Cadby (Geneva) for his technical assistance.

\section{References}

1. Larsen AI, Olsen J, Svane O. Gender-specific reproductive outcome and exposure to high-frequency electromagnetic radiation among physiotherapists. Scand J Work Environ Health 1991;17:324-9.

2. Larsen AI. Congenital malformations and exposure to high-frequency electromagnetic radiation among Danish physiotherapists. Scand J Work Environ Health
1991;17:318-23.

3. Skotte J. Reduction of radiofrequency exposure to the operator during short-wave diathermy treatments. J Med Eng Technol 1986;10:7-10.

4. Larsen AI, Skotte J. Can exposure to electromagnetic radiation in diathermy operators be estimated from interview data?: a pilot study. Am J Ind Med 1991;19: $51-7$.

5. Geigy scientific tables. 7th ed. Basel: Ciba-Geigy SA, 1972:85-103.

6. Taskinen H, Kyyrönen P, Hemminki K. Effects of ultrasound, shortwaves, and physical exertion on pregnancy outcome in physiotherapists. J Epidemiol Community Health 1990;44:196-201.

7. Källén B, Malmquist G, Moritz U. Delivery outcome among physiotherapists in Sweden: is non-ionizing radiation a fetal hazard? Arch Environ Health 1982; $37: 81-5$.

Received for publication: 23 November 1993 